\title{
The Development of Indonesia Environmental Performance and Environmental Compliance
}

\author{
Sofik Handoyo \\ Department of Accounting - Faculty of Economics and Business \\ Universitas Padjadjaran
}

\begin{abstract}
This study aims to analyze the development of Indonesia environmental performance and environmental compliance from the period 2011-2015 through the PROPER program. Statistic descriptive, along with trend analysis, was applied in this study. The result indicates that achievement of the environmental performance of the PROPER program is on adequate level $(63,2 \%)$, Poor level $(25,9 \%)$, good level $(7,5 \%)$, very poor $(2.8 \%)$ and excellent level $(0.6 \%)$. Meanwhile, Indonesia environmental compliance level on average is $72 \%$. There is still $28 \%$ of the PROPER participant not comply with environmental requirements determined by the Ministry of Environment (MOE). The achievement of environmental compliance consists of beyond compliance $(12 \%)$ and adequate compliance $(88 \%)$.
\end{abstract}

Keywords: Environmental performance; Environmental compliance; Proper program, Compliance; Beyond compliance

\section{Introduction}

As a country with economy power continuously growing, Indonesia has turned gradually to be an industrial country. It is indicated by Indonesia position on a list of 20 countries that have a significant influence in terms of their economy. However, Indonesia's industrial expansion has brought with it mostly uncontrolled industrial wastes and pollution, leading to severe environmental degradation (Makarim and Butler, 1996). Indonesia rapid industrialization, population growth, and urbanization have created severe pollution problems (Blackman, 2004). As the structure of Industrialization in Indonesia is very much dependent on natural resources, Indonesia is a potential subject of receiving critics related to environmental issues. Environmental issues are frequently lifted as argumentation by developed country to ban developing countries in terms of their involvement in international trading. Therefore, keeping business entities always complying to the international standard of environmental protection is fundamental. In this case, the role of government is pivotal in order to maintain an image as an industrial country with the environmental friendly trademark.

Since environmental problems rose to prominence in the last third of the twentieth century, the nation-state has been an active scale of governance for addressing them 
(Fiorino, 2011). Sustainability economy, along with sustainability environment, is a dream of a global society. The momentum of sustainability economy was triggered by the World Commission on Environment and Development in the late 1980s and Rio de Janerio Earth Summit of 1992 (Fiorino, 2011). Declining environmental quality, global warming, climate changes, natural disaster are considered as the impact of irresponsible economic activities. Indonesia, as part of the world community, has a responsibility to make the world a better place for living along with economic development. As a member of G20 and Kyoto Protocol, Indonesia has a responsibility to contribute in terms of preventing business activities that are the damaging environment. Triple bottom line agenda (People, Planet, and Profit) is in a vision of the Indonesia government to be achieved. The concern of the Indonesia government to environmental issues was reflected by forming institution such as BAPEDAL (Environmental Impact Management Agency) and issued several environmental laws and regulations intended to protect the environment from harmful impact of business activities

The first policy of Indonesia in terms of action to prevent the negative impact of industrialization was applying command and control approach. The government releases specific rules and regulation related to environmental protection, and the business entities were expected to comply with those rules and regulation. However, this approach did not work effectively to make business entities comply with environmental rules and regulation. Countries such as Indonesia face a tough challenge in choosing and designing policy instruments to deal with industrial pollution (Garcia et al., 2008 and 2009). On the side of government, weakness of law enforcement, limited budget for controlling and monitoring were considered as significant factors made command and control approach failed (Makarim et al., 1995, Afsah et al., 2009, Garcia et al., 2008 and 2009). Meanwhile, business entities argue that complying to environmental issues is costly. Therefore, they need an incentive as a return of investment in any part of the business process related to environmental issues. Based on these circumstances, the government needs a new alternative to cope ineffectiveness of command and control environmental protection program.

As a response to weakness command and control environmental program and to support agenda sustainability economic development and sustainability environment, in June 1995, Indonesia Ministry of Environment (MOE) launched the PROPER program. PROPER program is a program for pollution control, evaluation, and rating (Makarim et al., 1995). The Program was designed to use public disclosure, environmental awards, and reputational incentives as the motivating forces for environmental improvement (Afsah et al., 2011). The basic idea of PROPER was to use public disclosure of firms' environmental indicators as a substitute for enforcement (Garcia et al., 2009). Under the PROPER program, businesses entities are rated by the environmental impact agency of MOE, based on clearly articulated criteria. The results of this rating are reflected in a single index that is widely publicized (Makarim and Butler, 1996).

The environmental authority understood that disclosing raw data could create interpretation problems among the public ( Garcia et al., 2008), therefore, the color rating system was designed to be simple enough to be easily understood by the public and still convey enough information to influence behavior (Lopez et al., 2004, Makarim and Buttler, 1996). A color-coded rating scheme was developed under the PROPER program to grade factories' 
performance against the regulatory standards (Kanungo and Torres, 2003). Environmental performance of companies is mapped into a five-color grading scale; gold for excellent, green for good, blue for adequate, red for poor, and black for very poor. Based on PROPER color index, MOE classifies gold, green and blue as environmentally comply. Meanwhile, the red and black color index is not complying to the environment

Furthermore, categorization of environmentally comply itself is divided into two forms, beyond compliance for gold and green color index and adequate compliance for the blue color index. Adequate compliance criteria are a minimum standard to be achieved by PROPER participants in order to be awarded environmentally comply. The criteria include environmental documents and reporting requirements, water pollution control, management of hazardous and toxic waste, seawater pollution control, and potential of land degradation (MOE, 2013).

If adequate compliance criteria are essential criteria to be called environmentally comply, the beyond compliance criteria is more dynamic because it is adapted to the development of technology, the application of best practices in environmental management practices and global environmental issues (Arsyad, 2012). Beyond compliance criteria includes; the implementation of an environmental management system, energy efficiency efforts, efforts to reduce emissions, the implementation of reduce, reuse and recycle of hazardous and toxic waste, the implementation of reduce, reuse and recycle of solid non-hazardous and toxic waste, water conservation and wastewater pollution, load reduction, the protection of biodiversity, community development program (MOE, 2013)

The results are disseminated through the website of MOE and various publication media. Due to extensive range stakeholder involvement, the PROPER program is also called as public disclosure for environmental performance. For the companies involved in the encasement of PROPER program, it can be used as an image company building and expected can increase the value of the company. For MOE on behalf of the Indonesian government, the PROPER program is a form of real action to create balancing both sustainability economy and sustainability environment.

PROPER program is an innovative attempt to mitigate the problems associated with pollution under the umbrella of the government of Indonesia's environmental impact agency (Kanunggo and Torres, 2003). The program's objective is to act as a regulatory mechanism which can promote and enforce compliance with pollution control standards, encourage pollution reduction, introduce the concept of "clean technology," and promote an environmental management system through the use of incentives and transparency (Kanunggo and Torres, 2003).

Indonesia's program for pollution control evaluation and rating (PROPER) was the first significant initiative in the developing world that used information disclosure to reduce industrial pollution (Garcia et al., 2009). The PROPER program was built on the premise that the mechanisms of public disclosure and accountability, transparency in operations, and community participation will empower local communities to achieve effective and sustained pollution control practices (Kanunggo and Torres, 2003).

As an environmental performance index of one country supposes to be related to the environmental performance of business entities in that country, then the question is pointed to the effectiveness of the PROPER program itself. Therefore, we need to understand more in detailed the performance 
development of the program for pollution control, evaluation, and rating (PROPER). Despite positive opinion from the international sphere about effectiveness PROPER program, however, there are still limited studies that analyze PROPER achievement in national level in term of its environmental performance level and environmental compliance level. Therefore, the research question of this study is to address the achievement of Indonesia environmental performance and compliance under PROPER Program.

The PROPER program has been two decades running since its first-time introduction in June 1995. Many appreciations and praised addressed to implementation of the PROPER program. However, a clear picture of the progress and achievement of the PROPER program is not quite well discussed in the academic sphere. Plenty of studies revealed the relationship between good corporate governance, stock price, profitability, and PROPER achievement. However, there is very limited information about the current standing of achievement of the PROPER program at the national level. Therefore, there is a need to understand the development of environmental performance and environmental compliance under the PROPER program. General-purpose of this study is aimed to give exposure of Indonesia program for pollution control, evaluation and rating (PROPER) and presenting current standing of environmental performance and environmental compliance of Indonesian companies participated in the PROPER program. Specific purposes of this study are to identify and measure PROPER participants in term of two aspects, first, the development of environmental performance level and second, the development environmental compliance level.

\section{Research Methodology}

This study applied the descriptivequantitative approach. The quantitative data are presented in particular formats such as a table, graph, and diagram. The information is verbally analyzed using trend analysis approaches. This study used secondary quantitative data to be analyzed. The data was collected from the open publication of MOE, which is from the official website of MOE. The period of observation is from 2011-2015. For the measurement level of environmental performance and level of environmental compliance, formula from MOE was adopted.

Level of Environmental Performance (LoP) was measured from the percentage of the number of PROPER rating each category (excellent, good, adequate, poor and very poor) of total PROPER participants. The brief formula to calculate the level of environmental performance adopted from MOE is presented as follows:

$$
\text { LoEP }=\frac{\text { PROPER Rating each category }}{\text { Total PROPER Participant }} \times 100 \%
$$

Meanwhile, measurement of Level of environmental compliance (LoEC) was calculated from the percentage of accumulation environmentally comply PROPER rating of total PROPER participants. Environmentally comply rating consists of excellent rating $(\mathrm{E})$, good rating (G), and adequate rating (A) Detail of the formula is presented as follows:

$$
\text { LoEC }=\frac{\text { PROPER Rating E }+\mathrm{G}+\mathrm{A}}{\text { Total PROPER Participant }} \times 100 \%
$$




\section{Results and Analysis}

\section{Environmental Performance}

PROPER program is a voluntary environmental program assessment for business enterprises, governmental agencies, and not for profit organization. Even though the program itself requires no obligation in terms of involvement for the organizations, however, the participants of the PROPER program indicates increasing trend every year. Graphic 1 shows that there is a positive trend of PROPER participant each year from the period $2011-2015$

Graphic 1. PROPER Program Participants

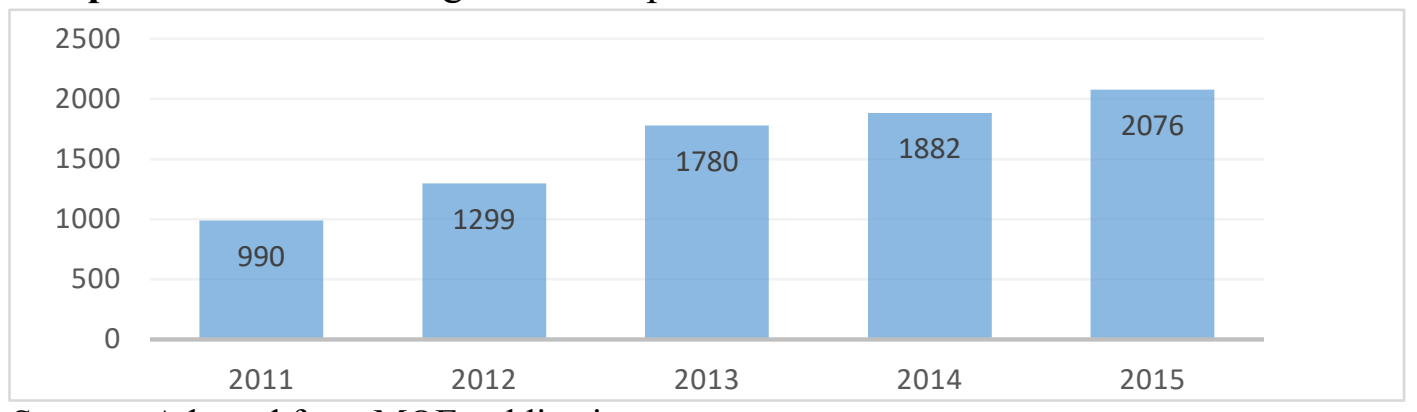

Sources: Adapted from MOE publication

The increasing trend is $31 \%$ for period 2011-2012, 37\% for period 20122013, 5\% for period 2013-2014 and 9\% for period 2014-2015. It takes the implication that business enterprises, governmental agencies, and not for profit organization in Indonesia consider seriously about environmental issues. Initiative to voluntary involve in PROPER program assessment is possibly driven by understanding among them that nowadays, the organization should not only concern about products or services they provide, but also the responsibility to environmental issues. The more educated customers, the more rationale customers make a decision about their preferences to buy a product or services. Involvement in the PROPER program could be an organization's strategy to attract customers.

PROPER participants have measured their environmental performance into five categories, namely excellent, good, adequate, poor and very poor. The distribution of environmental performance in terms of the number of achievement each category is presented in table 1 . Table 1 depicts that the most noticeable progressive PROPER level of environmental performance is adequate and poor. Meanwhile, excellent, good and very poor level is relatively no significant changes from time to time

Tabel 1. Proper Rating Distribution

\begin{tabular}{llllll}
\hline Environmental Rating & $\mathbf{2 0 1 1}$ & $\mathbf{2 0 1 2}$ & $\mathbf{2 0 1 3}$ & $\mathbf{2 0 1 4}$ & $\mathbf{2 0 1 5}$ \\
\hline Excellent & 5 & 12 & 12 & 9 & 12 \\
Good & 106 & 119 & 113 & 121 & 108 \\
Adequate & 603 & 806 & 1099 & 1224 & 1406 \\
Poor & 233 & 295 & 551 & 516 & 529 \\
Verry Poor & 48 & 79 & 17 & 21 & 21 \\
Total & $\mathbf{9 9 0}$ & $\mathbf{1 2 9 9}$ & $\mathbf{1 7 8 0}$ & $\mathbf{1 8 8 2}$ & $\mathbf{2 0 7 6}$ \\
\hline
\end{tabular}

Sources: Adapted from MOE publication 
If we briefly look at the increasing number of PROPER adequate ratings, the first impression may be sound good to the readers. However, these number can lead us to misjudgment if not carefully understand the profile of PROPER participants each year. The increasing number of an adequate rating does not mean that there is an upgrading level of environmental performance, and increasing poor rating is not always associated with the downgrading of environmental performance. The increasing number is actually driven by the number of PROPER participants that increased every period. Therefore, we need to analyze more detail each PROPER achievement relative to the total participant.
The trend of the PROPER participant from 2011 to 2015, as mentioned in figure 1 shows that the number of PROPER participants increased each year significantly. Based on that information, if it is associated with the data on table 1, we can assume that majority of new PROPER participants mostly fall into adequate and poor rating and there is not significant upgrading rating of excellent and good rating. Especially for excellent and good rating achiever, the number indicates relatively the same even decreasing in a certain period. It implies that for most PROPER participants, it is challenging to upgrade their environmental performance from low level to upper level (good to excellent, adequate to good, poor to good)

Table 2. PROPER Level of Environmental Performance

\begin{tabular}{lcccccc}
\hline Environmental Rating & $\mathbf{2 0 1 1}$ & $\mathbf{2 0 1 2}$ & $\mathbf{2 0 1 3}$ & $\mathbf{2 0 1 4}$ & $\mathbf{2 0 1 5}$ & Average \\
\hline Excellent & $0.5 \%$ & $0.9 \%$ & $0.7 \%$ & $0.5 \%$ & $0.6 \%$ & $0.6 \%$ \\
Good & $10.7 \%$ & $9.1 \%$ & $6.3 \%$ & $6.4 \%$ & $5.2 \%$ & $7.5 \%$ \\
Adequate & $60.6 \%$ & $61.5 \%$ & $61.3 \%$ & $64.7 \%$ & $67.7 \%$ & $63.2 \%$ \\
Poor & $23.4 \%$ & $22.5 \%$ & $30.8 \%$ & $27.3 \%$ & $25.5 \%$ & $25.9 \%$ \\
Very Poor & $4.8 \%$ & $6.0 \%$ & $0.9 \%$ & $1.1 \%$ & $1.0 \%$ & $2.8 \%$
\end{tabular}

Sources: Adapted from MOE publication

Table 2 depicts the result of the PROPER level of environmental performance by each category relative to the total PROPER participant. If we look at the number, there is a trend of decreasing PROPER performance level for good and very poor. In contrary, adequate environmental performance level tends to increase. Meanwhile, the others (excellent and poor) indicates fluctuate trend. To get a visual understanding of the trend, the trend level of environmental performance is presented in graphic 2. The graphic shows that there is a decreasing and fluctuating trend from year to year; however, the changes in trend indicate not significant in terms of the number. Therefore, we can use the average number to identify the level of the environmental performance of the PROPER program.

Based on data presented in table 2, we can analyze that the average level of environmental performance indicates that the majority $(63,2 \%)$ of proper participants is on an adequate level. On the second, third, fourth and fifth rank respectively is poor level $(25,9 \%)$, good level $(7,5 \%)$, very poor level $(2.8 \%)$ and excellent level $(0.6 \%)$. It indicates that the environmental performance of PROPER participants mostly is on the 
adequate and poor level. It means that level of environmental of PROPER participants is still not in the ideal position. Environmental performance is categorized in the ideal position if the level performance achievement lies mostly on good and excellent level.

Graphic 2. The trend of the PROPER level of Environmental Performance

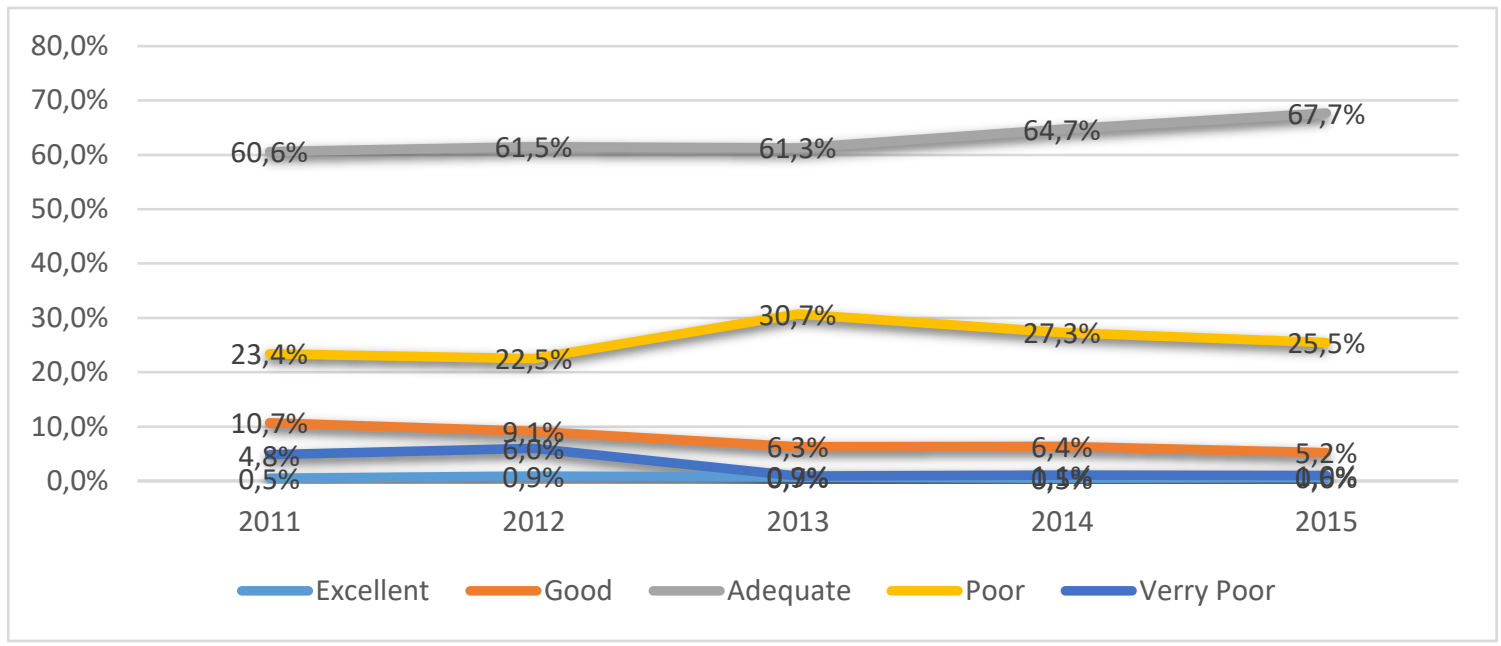

\section{Environmental Compliance}

MOE has certain standard to identify the compliance of that PROPER participants. Excellent, good and adequate environmental performance rating are classified as the entities that comply with environmental issue determined by MOE. Furthermore, MOE classifies compliance level in more detailed into two categories, adequate compliance and beyond compliance. Beyond compliance is awarded to the entities that achieve excellent and good environmental rating.

Meanwhile, entities are rated as adequate compliance if the achievement of environmental performance is only on adequate rating. The rest, poor and very poor environmental performance rating is counted as environmentally not comply. The entities categorized as environmentally not comply with the PROPER participant that are not meeting with minimum requirement determined by MOE. Table 3 depicts the PROPER rating achievement from 2011 to 2015. The data indicate that the level of environmental compliance fall between $69 \%$ to $73 \%$ and with average environmental compliance on $72 \%$.

Table 3. PROPER Rating Achievement and Level of Compliance

\begin{tabular}{lrrrrr}
\hline & $\mathbf{2 0 1 1}$ & $\mathbf{2 0 1 2}$ & $\mathbf{2 0 1 3}$ & $\mathbf{2 0 1 4}$ & $\mathbf{2 0 1 5}$ \\
\hline Excellent & 5 & 12 & 12 & 9 & 12 \\
Good & 106 & 119 & 113 & 121 & 108 \\
Adequate & 603 & 806 & 1099 & 1224 & 1406 \\
Poor & 233 & 295 & 551 & 516 & 529 \\
Very Poor & 48 & 79 & 17 & 21 & 21 \\
Total Participant & 990 & 1299 & 1780 & 1882 & 2076 \\
Level of Compliance & $\mathbf{7 2 \%}$ & $72 \%$ & $69 \%$ & $72 \%$ & $73 \%$ \\
\hline Level of Compliance on Average & \multicolumn{7}{c}{$\mathbf{7 2 \%}$} \\
\hline
\end{tabular}


Sources: Adapted from MOE publication

The trend of the level of compliance relatively smooth from $2011-2015$, except for the year 2013, there is a slightly decreasing trend. The data implies that from 2011-2015 on average, $72 \%$ of total PROPER participants are already complying with environmental issues determined by MOE. It means that there are still $28 \%$ of PROPER participants in category environmentally not comply. Even though the number of PROPER participants that already comply with environmental issues relatively higher compared to those that are not, however, the compliance trend is relatively stagnant. In other words, there is no improvement in terms of the level of environmental compliance between 2011 to 2015. It implies that new PROPER participants that are voluntary involve in PROPER program, 72\% of them got compliance award, and the rest is not.

Graphic 3 may give us visual understanding that the trend of PROPER environmental compliance is relatively stagnant, even decreasing in a certain period. It indicates that no significant increasing environmental compliance performance in the period 2011-2015. There are many logical argumentations to explain the phenomena of stagnation of environmental compliance in Indonesia. However, based on the data, we can say that poor and very poor environmental rating achiever are unable to upgrade to a higher level and the new PROPER participants are fail to pass minimum requirement of environmental compliance determined by $\mathrm{MOE}$

Graphic 3. Trend of PROPER Environmental Compliance

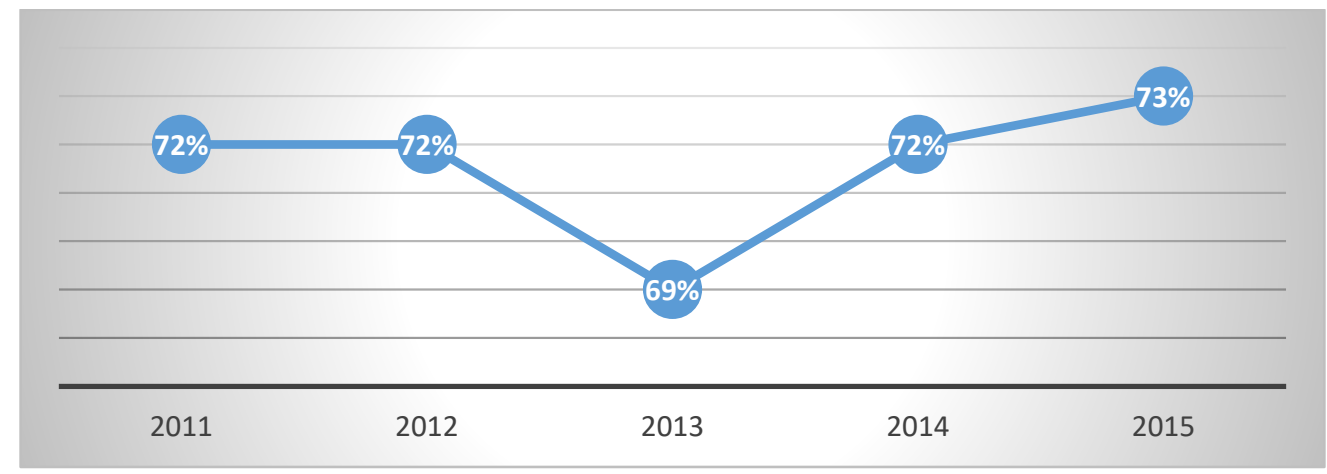

Environmental compliance rating Program (PROPER) by MOE is voluntary for the organization in terms of its participation. There is no severe consequence from MOE if the PROPER participant gets environmentally not comply rating. This reason drives the PROPER participants not put particular attention on how to improve their position from not environmentally comply to environmentally comply. They may just show their participation as part of good citizenship motive, but not really for the sake of environmental itself. Furthermore, PROPER rating award is not commercially influential for the business organization to create an image as an environmentally friendly organization compared to an award issued by ISO organization. However, those argumentations to explain the phenomena of stagnation of environmental compliance are merely based on logical thinking. In order to get factual information to deal with that question, further research should be conducted in more detailed

The achievement of PROPER 
compliance with $72 \%$ on average may give the readers a good enough impression. However, to understand the quality of compliance, the analysis more detailed is required. Graphic 4 depicts diagram chart of composition compliance level based on three categories level, excellent, good, and adequate. Most noticeable compliance level in that diagram chart is an adequate level achievement. From 2011 to 2015, the compliance level with adequate achievement was $88 \%$ on average. It means that $72 \%$ of PROPER participants that are categorized as environmentally comply, $88 \%$ of them only achieve an adequate level. The adequate level is the minimum level of environmental compliance achievement.

Table 4. Gives more detail information classification of PROPER compliance level into beyond compliance and adequate compliance category

Graphic 4. Composition of PROPER Compliance

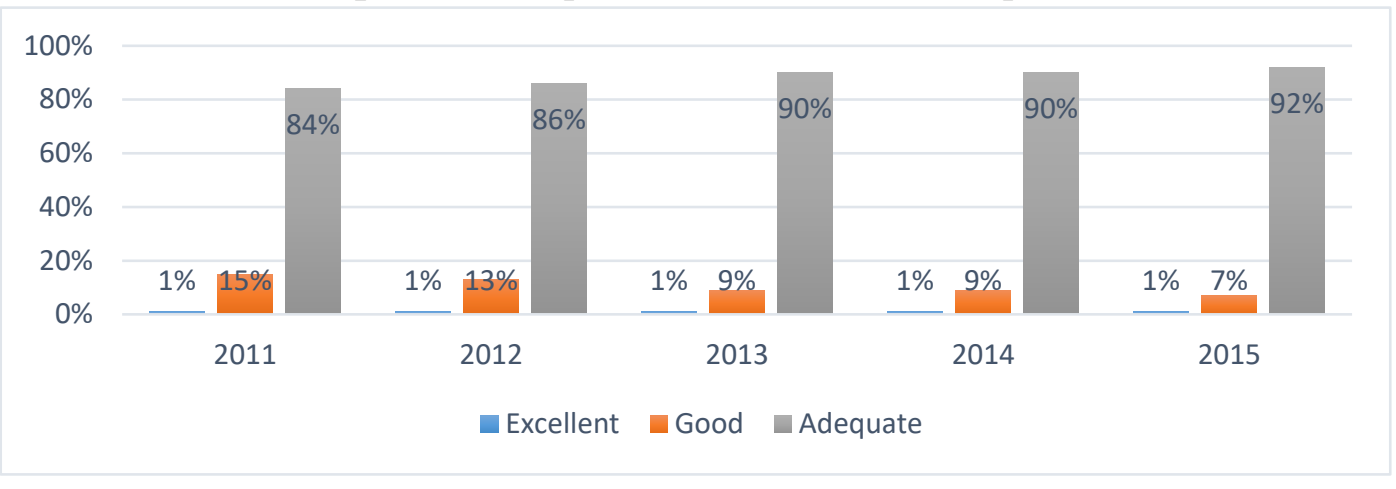

Based on information stated in table 4 , it indicates that on average only $12 \%$ of PROPER participants that are categorized as environmentally comply achieving beyond compliance rating (excellent and good level achievement). If the interpretation of compliance is based on its quality, it means that on average, PROPER compliance achievement is adequate compliance reaching $88 \%$ and $12 \%$ of the rest is beyond compliance. Compliance with adequate rating is the lowest level to be called environmental compliance. Therefore, we can say that PROPER participants awarded with achievement environmentally comply the majority only achieve the lowest level of compliance. It refers to an adequate level of environmental performance, which is compliance award that is given if the PROPER participant was passing minimum criteria determined by MOE. It implies that the achievement of $72 \%$ compliance is not quite impressive if it is revealed in more detail. The quality of compliance level is high if the majority of the PROPER participant is on beyond compliance rating (excellent and good)

Table 4. Compliance and Beyond Compliance

\begin{tabular}{lllllll}
\hline & $\mathbf{2 0 1 1}$ & $\mathbf{2 0 1 2}$ & $\mathbf{2 0 1 3}$ & $\mathbf{2 0 1 4}$ & $\mathbf{2 0 1 5}$ & Average \\
\hline Adequate Compliance & $84 \%$ & $86 \%$ & $90 \%$ & $90 \%$ & $92 \%$ & $88 \%$ \\
\hline Beyond Compliance & $16 \%$ & $14 \%$ & $10 \%$ & $10 \%$ & $8 \%$ & $12 \%$
\end{tabular}

Sources: Adapted from MOE publication 
To get a visual understanding of the trend of quality compliance level, the data from Table 4 is transformed into graphics presented in Graphic 5. From that diagram chart, it can be noticed that there is a decreasing trend for beyond compliance level and an increasing trend for compliance level. It means that there is a decreasing quality trend of PROPER environmental compliance from period 2011 to 2015.

Graphic 5. The trend of PROPER compliance and PROPER beyond compliance

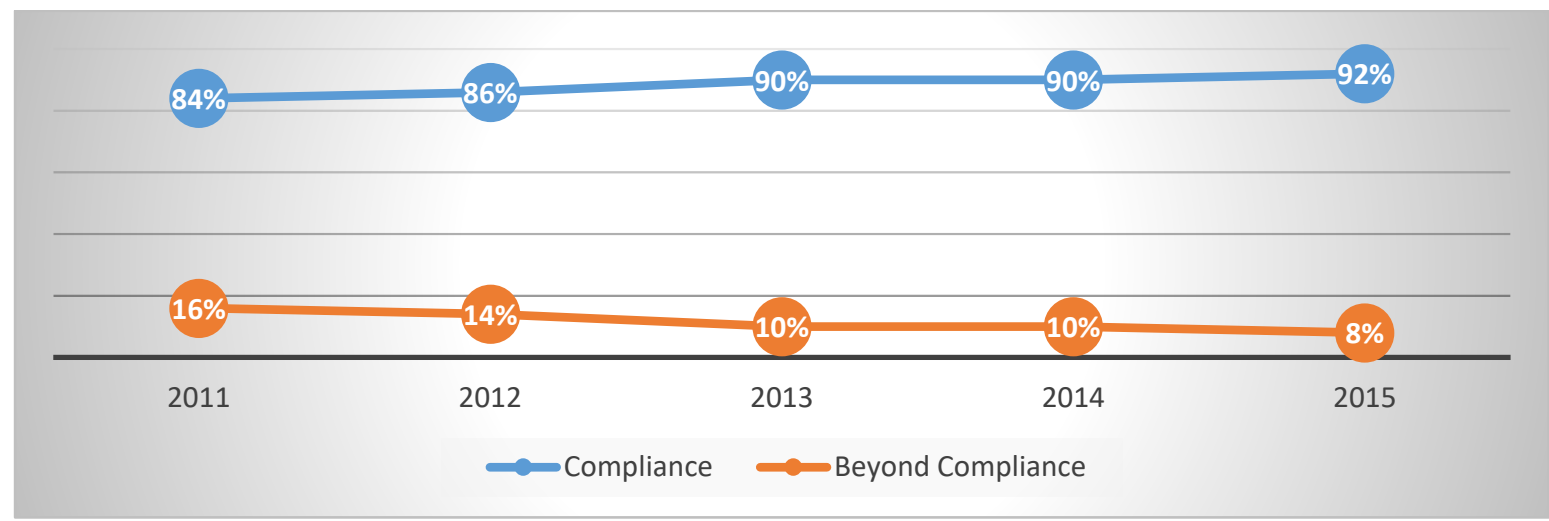

Referring to table 3, as mentioned before, the number of excellent and good rating was not in a decreasing trend. However, the distribution of adequate rating was increasing significantly time by time. This condition, made beyond compliance level relatively decreasing to overall compliance. It can be interpreted that decreasing quality of environmental compliance for beyond compliance (excellent and good rating) was not caused by degradation, but increasing trend of adequate compliance level. The bottom line of that trend is that PROPER compliance level achieved was dominated by an adequate level of compliance, which is the minimum level of compliance and for the beyond compliance (excellent and good rating) no significant changes, even decreasing

\section{Conclusion}

In general, we can conclude that achievement of the environmental performance of Indonesia from the period 2011 - 2015 is at an adequate level.
Regarding the level of environmental performance based on its order, the achievement of environmental performance on average respectively is adequate level $(63,2 \%)$, Poor level $(25,9 \%)$, good level $(7,5 \%)$, very poor $(2.8 \%)$ and excellent level $(0.6 \%)$. It indicates that the level of the environmental performance of Indonesia is dominated by adequate performance achievement. General understanding says that environmental performance is getting appreciation from the world community if the achievement is on level good and excellent. Therefore, there is a need to improve the environmental performance of Indonesia to a higher level. In this case, the role of authority like MOE is very pivotal. The PROPER program in the future should be no longer voluntary but an obligation. The authority should also consider the penalties for those that are rated as poor and very poor environmental performance. By putting penalties mechanism in assessing environmental performance, it will drive the entities to improve their environmental performance.

In terms of environmental 
compliance level, on average, compliance level of PROPER program from the period $2011-2015$ is reaching $72 \%$. It takes the implication that there is still $28 \%$ of PROPER program participant not comply with environmental requirements determined by MOE. Even though the number of the compliance level is pretty impressive; however, in terms of quality of compliance, it shows poor achievement. A total number of $72 \%$ environmentally comply consists of $88 \%$ adequately compliance and $12 \%$ beyond compliance (excellent and good). It explains that the majority of PROPER participant that is rated environmentally comply by MOE only achieve the lowest level of compliance. In terms of the trend of environmental compliance achievement, from 2011 to 2015 there is no indication of an increasing trend, even decreasing in a certain period.

Analysis of both the PROPER level of environmental performance and PROPER level of environmental compliance indicates a stagnant trend of performance. The PROPER program is very much relying on social punishment as the impact of public dissemination of rating. However, it seems that the mechanism of public dissemination did not work correctly to upgrade compliance level and environmental performance level. Therefore, the Indonesian government, in this case, through MOE, should take necessary actions related efforts to improve the level of environmental compliance and level of environmental performance. Those actions refer to actions such as giving fines or stopping operation permits for entities that obtained not compliance predicate. In order to improve performance from compliance to upper-level compliance, which is beyond compliance, MOE can issue a regulation to forces effort of adequate and good compliance receiver to upgrade their compliance level. With instrument such as fines, operational permits, and regulations are expected that PROPER program participant will seriously consider taking necessary efforts in order to improve their environmental compliance and environmental performance level

\section{References:}

Afsah, Shakeb., García Jorge., and Sterner, Thomas. The Institutional History Of Indonesia's Environmental Rating And Public Disclosure Program (Proper). 2011

Arsyad, Ibrahim. The Gold for Green. Publication Series Ministry of Environment of Indonesia. 2012

Blackman, Allen., Afsah, Shakeb and Ratunanda, Damayanti. How Do Public Disclosure Pollution Control Programs Work? Evidence from Indonesia. Human Ecology Review, Vol. 11, No. 3, 2004

Fiorino, Daniel J. Explaining National Environmental Performance: Approaches, Evidence, and Implications. Policy Sci (2011)

García, Jorge H.,Shakeb Afsah, and Sterner, Thomas. What Kinds of Firms Are More Sensitive to Public Disclosure Programs for Pollution Control: The Case of Indonesia's PROPER Program. Environment for Development Discussion Paper Series, March 2008

García, Jorge H.,Shakeb Afsah, and Sterner, Thomas. Public Disclosure of Industrial Pollution: The PROPER Approach for Indonesia? Working Papers In Economics, No.414. Department of Economics School of Business, Economics, and Law at the University of Gothenburg. 2009 
Kanungo, Parameeta., and Torres, Magüi Moreno. Indonesia's Program For Pollution Control, Evaluation, And Rating (Proper). World Bank. 2003

Makarim, Nabriel, and Butler, John.
Information Sharing As An Environmental Policy Tool: The Indonesian Experience. Proceeding Fourth International Conference on Environmental Compliance and Enforcement. 1996 